\title{
Copanlisib for the Treatment of Malignant Lymphoma: Clinical Experience and Future Perspectives
}

\author{
Javier Munoz ${ }^{1}\left[\right.$ George A. Follows ${ }^{2} \cdot$ Loretta J. Nastoupil $^{3}$
}

Accepted: 3 February 2021 / Published online: 9 March 2021

(c) The Author(s) 2021

\begin{abstract}
Dysregulation of phosphatidylinositol 3-kinase (PI3K)/protein kinase B/mammalian target of rapamycin signaling is common in both indolent and aggressive forms of malignant lymphoma, for which several targeted therapies have been developed. Copanlisib is a highly selective and potent intravenous pan-class I PI3K inhibitor that has demonstrated durable objective responses and a manageable safety profile in heavily pre-treated patients with indolent lymphomas. As a result, copanlisib monotherapy received accelerated approval from the US Food and Drug Administration for the treatment of adults with relapsed follicular lymphoma who have received at least two systemic therapies, and breakthrough designation for patients with pre-treated relapsed or refractory marginal zone lymphoma. Hyperglycemia and hypertension are among the most frequently reported adverse events with copanlisib monotherapy, and are infusion-related, transient, and manageable with standard therapies. Mild diarrhea is also a common adverse event with copanlisib monotherapy; there is no evidence of worsening severity of diarrhea, or serious gastrointestinal toxicities such as colitis or severe liver enzyme elevations, which have been reported with orally administered PI3K inhibitors. The intravenous route of administration and intermittent dosing schedule of copanlisib may support a favorable tolerability profile over continually administered oral alternatives. Ongoing studies of copanlisib in combination with rituximab and standard-of-care chemotherapy in patients with relapsed indolent lymphoma have the potential to support the use of copanlisib in the second-line setting, providing a much-needed additional therapeutic option in this underserved patient population.
\end{abstract}

\section{Introduction}

Phosphatidylinositol 3-kinase (PI3K)/protein kinase B $(\mathrm{AKT}) /$ mammalian target of rapamycin (mTOR) signaling is a vital intracellular pathway, regulating fundamental cell functions including cell growth, survival, and proliferation $[1,2]$. PI3K/AKT/mTOR signaling also plays a pivotal role in several metabolic processes, including mediating insulin and glucose metabolism [3]. PI3Ks consist of a family of plasma membrane-associated lipid kinases, and are categorized into three classes [4]. Class I PI3Ks are heterodimers

Javier Munoz

1 Mayo Clinic, 5881 E. Mayo Boulevard, Phoenix, AZ 85054, USA

2 Department of Haematology, Addenbrooke's Hospital, Cambridge University Hospitals NHS Foundation Trust, Cambridge, UK

3 Department of Lymphoma/Myeloma, The University of Texas MD Anderson Cancer Center, Houston, TX, USA containing a catalytic subunit, p110, encoded by PIK3CA, PIK3CB, PIK3CD, or PIK3CG, which give rise to four isoforms (p110 $\alpha, \mathrm{p} 110 \beta, \mathrm{p} 110 \gamma$, and $\mathrm{p} 110 \delta)$, respectively, and a regulatory subunit, p85 [4]. Class I PI3Ks can generate phosphoinositide 3,4,5 trisphosphate, which is thought to be essential for PI3K-mediated oncogenicity, while class II and III PI3Ks lack this function [4]. Dysregulation and aberrant activation of PI3K can lead to a disturbance of healthy cell growth and survival, with subsequent neoplastic transformation $[4,5]$. PI3K has been implicated in the tumorigenesis of many human cancers, which makes it an attractive therapeutic target for cancer [5].

$\mathrm{PI} 3 \mathrm{~K} / \mathrm{AKT} / \mathrm{mTOR}$ signaling is frequently deregulated in malignant lymphoma, leading to uncontrolled proliferation of B cells [6]. Malignant lymphomas are heterogeneous and typically fall into two prognostic groups: indolent and aggressive [7, 8]. Follicular lymphoma (FL) and diffuse large B cell lymphoma (DLBCL) represent the most common forms of indolent and aggressive lymphoma, respectively [9]. For patients with FL, approximately $20 \%$ will experience early relapse and disease progression within 


\section{Key Points}

Copanlisib monotherapy has demonstrated durable and rapid objective responses in patients with heavily pretreated indolent lymphoma, with a manageable safety profile, and is approved for the treatment of patients with relapsed follicular lymphoma.

The intravenous route of administration and intermittent dosing schedule of copanlisib may support a favorable tolerability profile over continuously administered oral alternatives.

Ongoing studies are evaluating the safety and efficacy of copanlisib in combination with rituximab and standardof-care chemotherapy in patients with relapsed indolent lymphoma and may support the use of copanlisib in the second-line setting as part of a combination regimen if the results are positive.

24 months (POD24) following standard first-line chemotherapy, which is a predictor of lessened overall survival (OS) [9-13]. Evidence for activation of the PI3K/AKT/ mTOR pathway has been demonstrated in samples from FL and DLBCL patients, suggesting that activation of the pathway may be involved in the pathogenesis of non-Hodgkin lymphoma (NHL) [14-16].

Therapies, both oral and intravenous, have been developed to target different components of the PI3K/AKT pathway in malignant lymphoma; one selective PI3K- $\alpha$ and PI3K- $\delta$ inhibitor, copanlisib (Aliqopa; Bayer AG, Berlin, Germany), administered intermittently and intravenously once weekly for 3 weeks on and 1 week off, and two selective PI3K- $\delta$ inhibitors, idelalisib and duvelisib, administered orally on a continuous twice-daily schedule, have been approved for treatment of relapsed and refractory FL [17-19], with other novel therapies currently under investigation. However, high rates of autoimmune and infectious toxicities have raised concerns over the safety of orally administered PI3K inhibitors, resulting in US Food and Drug Administration (FDA) black box warnings for hepatotoxicity, diarrhea or colitis, pneumonitis, and intestinal perforation with idelalisib [18], and infections, diarrhea or colitis, cutaneous reactions, and pneumonitis with duvelisib [17, 20, 21]. Oral PI3K inhibitors have also demonstrated some tolerability issues in combination with earlier lines of therapy, and a number of combination studies were discontinued due to safety concerns [22]. In a phase I, open-label study of idelalisib in combination with bendamustine or rituximab in patients with chronic lymphocytic leukemia (CLL), 75\% developed significant serious adverse events (AEs), including infections, that were associated with the combination [23]. Similarly, a phase I study of duvelisib in combination with rituximab alone or rituximab and bendamustine in patients with CLL and relapsed/refractory NHL demonstrated toxicities that were consistent with those reported for the respective single agents [24]. Continued development of PI3K inhibitors has therefore been necessary in order to provide safe and effective treatment options for this underserved population. Targeted therapies under investigation include the oral PI $3 \mathrm{~K}-\delta$ inhibitor umbralisib, currently being evaluated in FL patients with POD24 (SWOG1608 study, NCT03269669). Umbralisib is being explored for the treatment of patients with previously treated marginal zone lymphoma (MZL) and FL in the UNITY-NHL phase IIb study [25]. The oral PI3K- $\delta$ inhibitor parsaclisib was also recently investigated in a phase II study of patients with relapsed or refractory DLBCL (CITADEL-202, NCT02998476); the study was terminated due to futility, but evaluation in combination with standard therapies is ongoing [26]. Other classes of agent in early clinical development in the third-line setting for patients with relapsed/refractory B cell lymphoma include CD19directed chimeric antigen receptor $\mathrm{T}$ cell immunotherapy [27-29], bi-specific anti-CD20/CD3 monoclonal antibodies (mosunetuzumab [30] and epcoritamab [31]), and the EZH2 inhibitor tazemetostat, which has recently obtained accelerated FDA approval for the treatment of patients with relapsed or refractory FL and mutated EZH2 who have been treated with at least two therapies [32].

Copanlisib is a highly selective and potent intravenous pan-class I PI3K inhibitor, with predominant activity against the PI3K- $\alpha$ and PI3K- $\delta$ isoforms [33]. Following the observation of promising anti-tumor activity in preclinical studies [33], the first-in-human phase I study of copanlisib established that copanlisib could be safely administered intravenously in a continuous 1-h infusion, on an intermittent schedule of days 1,8 , and 15 of a 28 -day cycle, with the maximum tolerated dose (MTD) identified as $0.8 \mathrm{mg} / \mathrm{kg}$ [34]. This phase I study, together with the subsequent pivotal phase II CHRONOS-1 study, demonstrated that copanlisib is safe and well tolerated, with the most common AEs being hyperglycemia and hypertension, both of which are known to be transient and manageable, and did not lead to significant treatment discontinuation during the studies [34-36]. Based on the phase II CHRONOS-1 study (NCT01660451; part B), copanlisib $60 \mathrm{mg}$ was granted accelerated approval by the FDA for the treatment of adults with relapsed FL who have received at least two systemic therapies, and does not have a black box warning regarding toxicities [37].

The intravenous route of administration and the intermittent schedule of dosing for copanlisib make it unique among PI3K inhibitors, both approved and in development. Here, we review the properties of copanlisib, summarizing the known efficacy and safety profile of copanlisib to date in 
studies including patients with indolent and aggressive types of lymphoma. We will consider the future of copanlisib and summarize ongoing clinical studies.

\section{Activity of Copanlisib in Preclinical and Clinical Studies}

Copanlisib has demonstrated potent anti-proliferative activity in multiple cell lines, with half maximal inhibitory concentration values of less than $10 \mathrm{nmol} / \mathrm{L}$ [33]. Consistent with the reported in vitro activity, intravenously administered copanlisib demonstrated anti-tumor activity in cellderived and patient-derived xenograft models [38], including in rat xenograft models derived from human colon tumors carrying PIK3CA and KRAS mutations, and mouse xenograft models established from patient-derived, erlotinib-resistant, non-small cell lung carcinoma and luminal breast cancer [33]. Interestingly, prolonged levels of copanlisib were seen in tumors compared with plasma after intravenous dosing, and a once-weekly schedule had similar anti-tumor effects as an every-other-day schedule. Together, the preclinical efficacy findings provided rationale to evaluate copanlisib in human studies.

Class I PI3Ks have been shown to play a key role in mammalian insulin signaling, linking the activation of the insulin receptor to glucose metabolism, with the PI3K- $\alpha$ and PI3K- $\beta$ isoforms primarily involved in this process $[39,40]$. Insulin-receptor signaling is driven by PI3K- $\alpha$ and PI3K- $\beta$ phosphorylation of AKT, with both isoforms demonstrating functional redundancy [39]. Dysregulation of PI3K signaling downstream of the insulin receptor has been shown to be a contributor to the pathophysiology of type 2 diabetes [41]. In vivo, reduced insulin sensitivity, impaired glucose tolerance, and increased gluconeogenesis have been observed in mice with a hepatic knockout of p110 $\alpha$ [42]. Accordingly, hyperglycemia has been a common and expected on-target effect of PI3K inhibition in phase I clinical studies [43-46], including in the first-in-human study of copanlisib, where hyperglycemia events were transient, asymptomatic, and manageable [34].

A phase I pharmacodynamic study has provided clear evidence of PI3K pathway on-target activity of copanlisib in patients with malignant lymphoma and advanced solid tumors, supporting a mode of action [47] (see Fig. 1). In that study, levels of pS6, a target downstream of phosphorylated AKT, exhibited dose-dependent reductions in lymphoma and solid tumor biopsies following treatment with copanlisib [47].

Immune cell types other than B cells have various functions in different tumor environments and can influence disease prognosis; for instance, high levels of $\mathrm{CD}^{+} \mathrm{T}$ lymphocytes and low levels of $\mathrm{CD}^{+} \mathrm{T}$ lymphocytes (comprising subsets of tumor-infiltrating lymphocytes) have been associated with a poor prognosis in patients with glioma [48]. In addition, there was a significantly higher $\mathrm{CD}^{+}$and $\mathrm{CD}^{+} \mathrm{T}$ lymphocyte count at the tumor-host interface than within the intratumoral stroma in a report of triple-negative breast cancer [49], and a high proportion of $\mathrm{CD}^{+}$cytotoxic $\mathrm{T}$ lymphocytes correlated with improved prognostic outcome in a report of non-small cell lung cancer [50]. In a small number of patients with malignant lymphoma and advanced solid tumors, a preliminary finding of dosedependent reduction in $\mathrm{CD}^{+}{ }^{+}$cells was observed in tumor
Fig. 1 Mode of action of copanlisib. FOXO Forkhead Box subfamily $\mathrm{O}$ transcription factors, GSK3 glycogen synthase kinase- $3, I C_{50}$ half maximal inhibitory concentration, $I R$ insulin receptor, $m T O R$ mammalian target of rapamycin, $p A K T$ phosphorylated AKT, $P D$ pharmacodynamic, $P I 3 K$ phosphatidylinositol 3-kinase, $R T K$ receptor tyrosine kinase

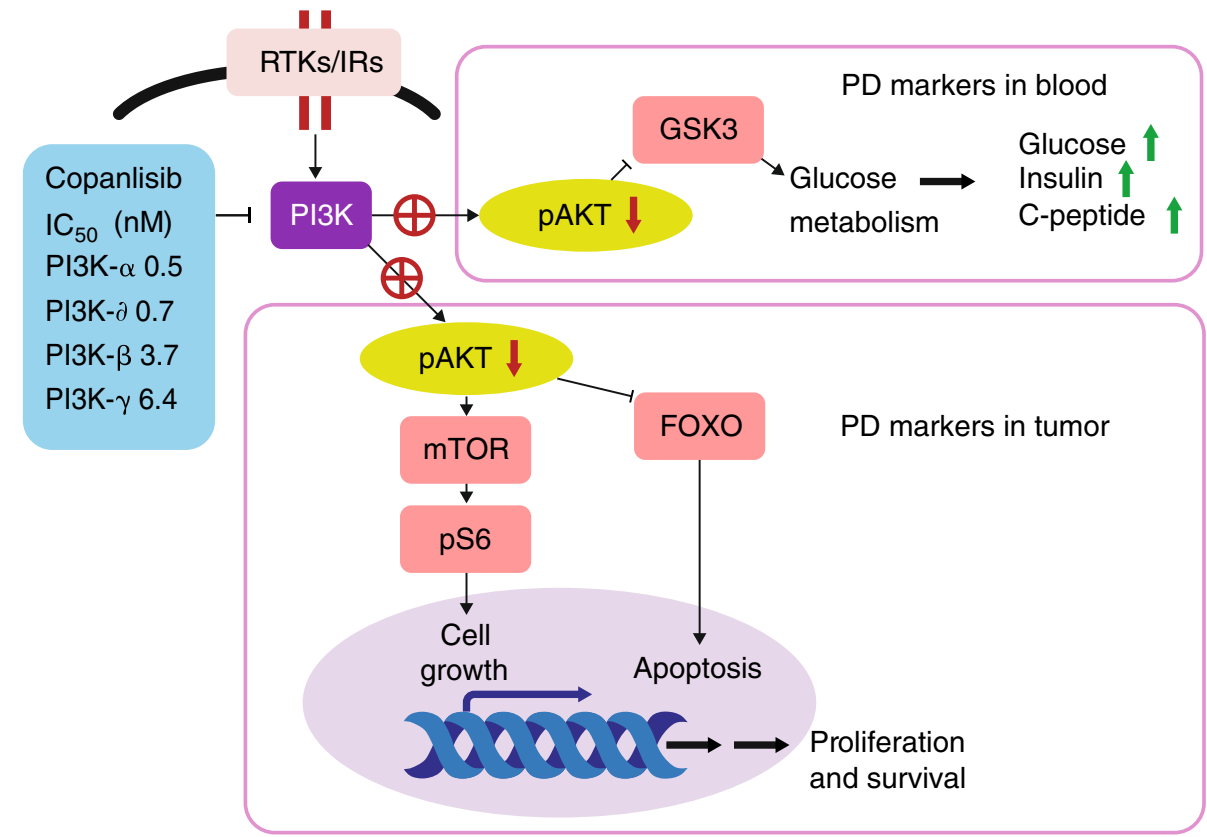


biopsies following copanlisib treatment compared with baseline, with little effect observed in the proportion of $\mathrm{CD}^{+}$ cells [47]. Although these results were not conclusive based on the small sample size, these data could suggest a role for copanlisib in immunosuppression through inhibition of the PI3K signaling pathway and warrant further investigation.

\section{Activity of Copanlisib Monotherapy in Indolent Lymphoma}

\subsection{Phase I Studies}

The first-in-human phase I study enrolled and treated six patients with FL in an NHL expansion cohort (nine patients in total), at the MTD level of $0.8 \mathrm{mg} / \mathrm{kg}$ intravenous copanlisib on days 1,8 , and 15 of a 28 -day cycle [51]. Promising efficacy outcomes were observed in patients with FL [34], summarized in Table 1. The separate phase I pharmacokinetic/pharmacodynamic study of copanlisib included one patient with grade $3 \mathrm{a}$ FL, who received intravenous copanlisib $0.8 \mathrm{mg} / \mathrm{kg}$ on the same intermittent schedule [47], and achieved a partial response (PR) as a best response (see Table 1).

\subsection{Phase II Studies}

Following the positive tolerability findings and early signs of efficacy in all FL patients treated in the first-in-human phase I study, an open-label phase II study (NCT01660451; part A) was initiated to evaluate copanlisib efficacy and safety in heavily pre-treated patients with relapsed or refractory malignant lymphoma [52]. This study enrolled and treated 33 patients with indolent lymphoma, including 16 patients with FL, 13 patients with CLL, three patients with MZL, and one patient with small lymphocytic lymphoma. Patients received intravenous copanlisib at the phase I MTD level, $0.8 \mathrm{mg} / \mathrm{kg}$, on the intermittent schedule (days 1,8 , and 15 of a 28-day cycle). Overall, 32 patients with indolent lymphoma had measurable lesions at baseline and were evaluable for response, with three patients achieving a complete response (CR) [including one with an unconfirmed CR]

Table 1 Summary of efficacy outcomes from clinical studies of copanlisib in patients with indolent lymphoma

\begin{tabular}{|c|c|c|c|c|}
\hline Study & Histology & $\begin{array}{l}\text { Number of } \\
\text { patients }\end{array}$ & ORR, \% (CR; PR) & $\mathrm{DCR}, \%(\mathrm{SD})$ \\
\hline \multicolumn{5}{|l|}{ Phase I } \\
\hline NCT00962611 [34] & FL & 6 & $100(2 ; 4)$ & $100(0)$ \\
\hline NCT02155582 [47] & FL & 1 & $100(0 ; 1)$ & $100(0)$ \\
\hline \multicolumn{5}{|l|}{ Phase II } \\
\hline \multirow[t]{4}{*}{ NCT01660451; part A [52] } & FL & $16^{\mathrm{a}}$ & $40.0\left(3^{\mathrm{b}} ; 3\right)$ & $93.3(8)$ \\
\hline & CLL & 13 & $38.5(0 ; 5)$ & $84.6(6)$ \\
\hline & MZL & 3 & $66.7(0 ; 2)$ & $100(1)$ \\
\hline & SLL & 1 & $100(0 ; 1)$ & $100(0)$ \\
\hline \multirow[t]{4}{*}{ NCT01660451; part B [35] } & FL & 104 & $58.7(15 ; 46)$ & $87.5^{\mathrm{c}}(35)$ \\
\hline & MZL & 23 & $69.6(2 ; 14)$ & $87.0(4)$ \\
\hline & SLL & 8 & $75.0(0 ; 6)$ & $87.5(1)$ \\
\hline & LPL/WM & 6 & $16.7(0 ; 1)$ & $66.7(3)$ \\
\hline \multirow[t]{4}{*}{ NCT01660451; part B long-term follow-up [36] } & FL & 104 & $58.7(21 ; 40)$ & $87.5\left(35^{\mathrm{d}}\right)$ \\
\hline & MZL & 23 & $78.3(3 ; 15)$ & $87.0(2)$ \\
\hline & SLL & 8 & $75.0(0 ; 6)$ & $87.5(1)$ \\
\hline & LPL/WM & 6 & $16.7(0 ; 1)$ & $66.7(3)$ \\
\hline $\begin{array}{l}\text { NCT01660451; part B FL POD24 subset (Leppä et al.; } \\
\text { submitted) }\end{array}$ & FL (POD24) & 68 & $60.3(15 ; 26)$ & $88.2(21)$ \\
\hline
\end{tabular}

$C L L$ chronic lymphocytic leukemia, $C R$ complete response, $D C R$ disease control rate, $F L$ follicular lymphoma, $L P L / W M$ lymphoplasmacytic lymphoma/Waldenström's macroglobulinemia, MZL marginal zone lymphoma, ORR objective response rate, $P O D 24$ progression within 24 months, $P R$ partial response, $S D$ stable disease, $S L L$ small lymphocytic lymphoma

${ }^{a}$ One patient was excluded because they did not have any measurable lesion as per Cheson criteria at baseline; therefore, 15 patients were evaluable for response

${ }^{\mathrm{b}}$ One patient achieved an unconfirmed CR

${ }^{\mathrm{c}}$ One patient with unconfirmed SD and four with SD or PR recorded $>35$ days from the last treatment were excluded

${ }^{\mathrm{d}}$ Includes one patient with unconfirmed early SD (SD was assessed earlier than 7 weeks after start of treatment, with no radiologic assessment of $\mathrm{SD}, \mathrm{PR}$, or CR at later cycles) 
and 11 with a PR as best response. The objective response rate (ORR) was $43.8 \%$, and the disease control rate (DCR) was $90.6 \%$ (15 patients with stable disease [SD]); Table 1 presents ORRs and DCRs per histology. Median time to response was 1.7 months (range 0-3.6) and median progression-free survival (PFS) was 9.7 months (range 0-28.7), with a median duration of response (DoR) of 12.8 months (range 0-27.1). Median OS was 21.6 months (range 0-31.5); at 12 months, OS was $69 \%$ [52].

Copanlisib demonstrated a promising efficacy profile in patients with indolent lymphoma in the phase I and phase II studies. Based on these results, the large, phase II CHRONOS-1 study (NCT01660451; part B) was initiated to evaluate copanlisib in patients with relapsed or refractory indolent B cell lymphoma [35]. A total of 142 patients with indolent lymphoma were enrolled and treated in CHRONOS-1, including 104 patients with FL, 23 patients with MZL, eight patients with small lymphocytic lymphoma, and six patients with lymphoplasmacytic lymphoma/Waldenström's macroglobulinemia (one patient was initially assessed by the investigator as having FL but was later confirmed to have DLBCL by the investigator and by central pathology review; this patient was included in the full analysis set). Patients in CHRONOS-1 received copanlisib $60 \mathrm{mg}$ as a 1-h infusion on the intermittent schedule of days 1,8 , and 15 of a 28 -day cycle; this was equivalent to the $0.8 \mathrm{mg} / \mathrm{kg}$ MTD intermittent dosing schedule as defined in the phase I study [34]. The overall ORR for the study was $59.2 \%$, exceeding the prespecified threshold of $40 \%$ (95\% confidence interval 51-67; $P<0.001$ ); ORRs and DCRs by histological subgroup are summarized in Table 1 . Patients with FL had an ORR of 59\% (including 15 CRs), and the patients with MZL had an ORR of $70 \%$ (including two CRs). Overall, median DoR was 22.6 months (range 0-22.6), with responses being rapid and durable (a median time to response of 53 days). Median PFS was 11.2 months (range 0.2-24.0), and median OS had not been reached by the data cut-off point. For patients with FL, median DoR was 12.2 months (range 0-22.6). Of 125 evaluable patients with indolent lymphoma in this study, 74 (59.2\%) exhibited at least a $50 \%$ reduction in target lesion size following treatment with copanlisib [35]. Based on the primary data from CHRONOS-1, copanlisib received accelerated approval from the FDA for the treatment of patients with relapsed FL who had received two or more therapies, adding to the available treatment options in the third-line setting for this advanced and heavily pre-treated population.

A 2-year follow-up of the 142 patients with indolent lymphoma from the phase II CHRONOS- 1 study showed that the responses to treatment with copanlisib seen at the time of the primary analysis were sustained and durable, even enhanced, over prolonged treatment [36]. At the time of the primary analysis, 17 and 67 patients achieved a CR and PR, respectively (ORR of 59.2\%) [35]. At the 2 -year follow-up, 24 and 62 patients achieved a CR and $\mathrm{PR}$, respectively, giving an ORR of $60.6 \%$; the increased proportion of patients with a CR is indicative of enhanced response to copanlisib over time [36]. In this 2-year followup analysis, six patients who initially had a PR achieved a $C R$, and one patient who had SD achieved a PR at the later cut-off. Of the seven additional CRs observed at the 2-year follow-up, six were observed in patients with FL and one was observed in a patient with MZL. The proportion of patients with SD remained unchanged, as did the overall DCR (85.9\%). Table 1 summarizes ORRs and DCRs per histology; the ORR in patients with FL was unchanged at the time of follow-up, whereas the ORR for patients with MZL increased from 70\% to 78\% (Panayiotidis et al.; submitted). Analyses at the 2-year follow-up showed short times to reach objective responses: the overall median time to response was 1.8 months (range 1.3-17.3), with a median of 4.7 months to CR (range 1.5-20.9). Overall, median DoR was 14.1 months (range 0.03-42.5), but was 26 months (range 1.9-34.5 months) in patients who had achieved a CR. Median PFS was 12.5 months (range 0.03-44.2 months), with a PFS rate at 2 years of $34 \%$. Median OS was 42.6 months (range 0.2-49.9), with an OS rate at 2 years of $69 \%$. Of 126 patients evaluable for lesion size, 116 patients $(92.1 \%)$ demonstrated a reduction in target lesion size, with 79 patients $(62.7 \%)$ demonstrating a reduction in size of at least $50 \%$ following treatment with copanlisib [36].

An exploratory analysis of the results from the 2-year follow-up of CHRONOS-1 focused on the effects of copanlisib treatment in patients with FL with POD24, a subset of patients deemed to be of highest risk [53,54] and representing a population with the greatest unmet clinical need. Of the 68 patients treated in CHRONOS- 1 with FL and with POD24, 15 and 26 patients achieved a CR and PR, respectively, giving an ORR of $60.3 \%$ (Leppä et al.; submitted), which was similar to the ORR for the overall FL population (58.7\%). Patients with FL with POD24 had a median DoR of 10.9 months (range 0-42.5), a median PFS of 11.3 months (range 0-44.2), and a median OS of 38.3 months (range 0.7-49.8); efficacy outcomes were broadly comparable with those of FL patients without POD24 (median DoR of 12.2 months [range 0-34.2], median PFS of 10.8 months [range 0-35.8], and median OS of 31.0 months [range 3.0-43.0]). These results reflect robust and durable responses in patients with FL regardless of disease progression status and including those with potentially high-risk disease, and the data indicate that copanlisib could be a viable therapeutic option for the most difficult to treat patients (Leppä et al.; submitted). 


\section{Activity of Copanlisib Monotherapy in Aggressive Lymphoma}

The first-in-human phase I study of copanlisib enrolled and treated three patients with DLBCL [34]. Patients received copanlisib $0.8 \mathrm{mg} / \mathrm{kg}$ as a single intravenous infusion over $1 \mathrm{~h}$ on days 1,8 , and 15 of a 28 -day cycle. Of these patients, one patient achieved a PR and two patients had progressive disease as best response (see Table 2).

In the open-label, phase II study of copanlisib in patients with relapsed and refractory malignant lymphoma, 51 patients with aggressive lymphoma were enrolled and treated with copanlisib $0.8 \mathrm{mg} / \mathrm{kg}$ on the intermittent dosing schedule (days 1, 8, and 15 of a 28-day cycle). Of these patients, 17 had peripheral $\mathrm{T}$ cell lymphoma (including three patients with anaplastic large-cell lymphoma and four patients with angioimmunoblastic T cell lymphoma), 15 had DLBCL, 11 had mantle cell lymphoma, six had transformed indolent FL, and one patient each had mediastinal large B cell lymphoma and grade $3 \mathrm{~b}$ FL. Of the 48 patients with aggressive lymphoma available for response, CRs and PRs were observed in four (two confirmed CRs and two unconfirmed CRs) and nine patients, respectively, resulting in an ORR of $27.1 \%$. Eleven patients had SD, giving a DCR of $50.0 \%$. Table 2 summarizes ORRs and DCRs by histology. Median time to response was 51 days (range 0-117) for the aggressive lymphoma cohort, median PFS was 70 days (range 0-897), and PFS at 12 months was 13\%. Median DoR was 166 days (range 0-786) and median OS was 183 days (range 0-1017), with a 12 -month OS rate of $42 \%$.

More recently, following on from the ORR of $6.7 \%$ in the DLBCL subgroup of patients treated with copanlisib in the phase II study in indolent and aggressive lymphoma [52], an open-label, phase II study was performed to evaluate the efficacy and safety of copanlisib specifically in patients with relapsed or refractory DLBCL [55]. In this study, two major molecular subtypes of DLBCL were evaluated, activated B cell-like (ABC) DLBCL and germinal center B cell-like (GCB) DLBCL, both of which have proven to differ in their clinical outcomes and responsiveness to treatment $[56,57]$. Patients received copanlisib $60 \mathrm{mg}$ as a $1-\mathrm{h}$ intravenous infusion on days 1,8 , and 15 of a 28-day cycle; overall, 19 and 30 patients with ABC DLBCL and GCB DLBCL, respectively, were evaluable for response. The ORR for all patients was $19.4 \%$. For patients with ABC DLBCL, four patients and two patients achieved a CR and PR, respectively, giving an ORR of $31.6 \%$ (see Table 2). Median DoR was 4.3 months (range 1.3-20.2), median PFS was 2.4 months (range 0.5-15.3), and median OS was 6.9 months (range 0.5-27.6). Of the 15 patients with $A B C$ DLBCL with calculable percentage changes from baseline in target lesions, seven patients (46.7\%) demonstrated a reduction in target lesion size of greater than $50 \%$. For patients with GCB DLBCL, one patient and three patients achieved a $\mathrm{CR}$ and $\mathrm{PR}$, respectively, resulting in an ORR of $13.3 \%$ (see Table 2). Median DoR was 6.0 months (range 2.1-20.2), median PFS was 1.7 months (range 0.03-21.9), and median

Table 2 Summary of efficacy outcomes from clinical studies of copanlisib in patients with aggressive lymphoma

\begin{tabular}{|c|c|c|c|c|}
\hline Study & Histology & $\begin{array}{l}\text { Number of } \\
\text { patients }\end{array}$ & ORR, \% (CR; PR) & $\mathrm{DCR}, \%(\mathrm{SD})$ \\
\hline \multicolumn{5}{|l|}{ Phase I } \\
\hline NCT00962611 [34] & DLBCL & 3 & $33.3(0 ; 1)$ & $33.3(0)$ \\
\hline \multicolumn{5}{|l|}{ Phase II } \\
\hline \multirow[t]{6}{*}{ NCT01660451; part A [52] } & PTCL & $17^{\mathrm{a}, \mathrm{b}}$ & $21.4(2 ; 1)$ & $57.1(5)$ \\
\hline & DLBCL & 15 & $6.7(0 ; 1)$ & $46.7(6)$ \\
\hline & MCL & 11 & $63.6\left(2^{\mathrm{c}} ; 5\right)$ & $63.6(0)$ \\
\hline & Transformed indolent FL & 6 & $33.3(0 ; 2)$ & $33.3(0)$ \\
\hline & Mediastinal large B cell lymphoma & 1 & 0 & 0 \\
\hline & $\mathrm{FL}^{\mathrm{d}}$ & 1 & 0 & 0 \\
\hline \multirow[t]{2}{*}{ NCT02391116 [55] } & ABC DLBCL & 19 & $31.6(4 ; 2)$ & $52.6(4)$ \\
\hline & GCB DLBCL & 30 & $13.3(1 ; 3)$ & $40.0(8)$ \\
\hline
\end{tabular}

$A B C$ activated B cell-like, $C R$ complete response, $D C R$ disease control rate, $D L B C L$ diffuse large B cell lymphoma, $F L$ follicular lymphoma, $G C B$ germinal center B cell-like, $M C L$ mantle cell lymphoma, $O R R$ objective response rate, $P R$ partial response, $P T C L$ peripheral T cell lymphoma, $S D$ stable disease

${ }^{a}$ Includes three patients with anaplastic large-cell lymphoma and four patients with angioimmunoblastic T cell lymphoma

${ }^{\mathrm{b}} 14$ patients with PTCL were evaluable for response

${ }^{\mathrm{c}}$ Includes two unconfirmed CRs

${ }^{\mathrm{d}}$ Grade $3 \mathrm{~b}$ 
OS was 9.4 months (range 0.2-29.4). Of the 24 patients with GCB DLBCL with calculable percentage changes from baseline in target lesions, four patients $(16.7 \%)$ had a reduction in target lesion size of greater than 50\%. Although the difference in ORR between ABC DLBCL and GCB DLBCL was not statistically significant $(P=0.1413)$ [55], these data appear to support preclinical studies suggesting that patients with ABC DLBCL may respond preferentially to PI3K inhibition, despite their worse prognosis, compared with patients with GCB DLBCL $[58,59]$.

\section{Safety}

Safety data from the first-in-human phase I study of copanlisib in patients with indolent and aggressive lymphoma demonstrated good tolerability with copanlisib [34]. Of the nine patients with malignant lymphoma included in the study (six with FL and three with DLBCL), the most common drug-related AEs (all grade) were hyperglycemia $(88.9 \%)$, nausea $(77.8 \%)$, hypertension, diarrhea, fatigue, and oral mucositis (33.3\% each) (see Table 3). Grade 3 and grade 4 drug-related AEs were observed in five patients $(55.6 \%)$ and one patient (11.1\%), respectively, with no drugrelated grade 5 events reported. Hyperglycemia and hypertension were the most frequent drug-related grade 3 AEs in this small cohort (33\% each), followed by drug-related rash/desquamation (11\%). Dose delays, interruptions, and reductions arising from drug-related AEs were observed in 14 patients (25\%), and four patients discontinued as a result of AEs. One drug-related AE leading to discontinuation was recorded: a dose-limiting toxicity (DLT) of left ventricular systolic dysfunction.

Safety data from the 84 patients with indolent and aggressive lymphoma from the phase II, part A study of copanlisib [52] reflected a safety profile consistent with the phase I study [34]. The most commonly reported treatment-emergent AEs (TEAEs) were hyperglycemia (59.5\%), hypertension (54.8\%), fatigue (48.8\%), diarrhea (40.5\%), and decreased neutrophil count $(34.5 \%)$ (see Table 3); in most cases, grade 3 was the worst grade of TEAE. There were ten deaths, including four considered possibly related to copanlisib. Serious TEAEs of grade 3, 4, and 5 were reported in 26 patients $(31.0 \%)$, four patients $(4.8 \%)$, and ten patients $(11.9 \%)$, respectively, with serious drug-related AEs recorded in $32.1 \%$ of patients. Permanent treatment discontinuation due to TEAEs was reported in $25 \%$ of patients. Dose interruptions or delays and dose reductions due to TEAEs were experienced by 50 patients $(59.5 \%)$ and 11 patients (13.1\%), respectively, with a median duration of dose interruption or delay of 1 week (range 0.1-1.7).

In the 142 patients with relapsed or refractory indolent lymphoma in the phase II, part B CHRONOS-1 study [35], the safety profile of copanlisib remained consistent with the previously discussed lymphoma cohorts [34, 52]; the most common TEAEs were hyperglycemia (50.0\%), diarrhea (33.8\%), fatigue, hypertension (30.3\% each), and decreased neutrophil count (29.6\%) (see Table 3). The most common grade 3 or 4 TEAEs were grade 3 hyperglycemia (34\%), grade 3 hypertension (24\%), grade 4 neutropenia (16\%), and grade 3 lung infection (13\%). There were six deaths (4\%), including three that were considered drug-related: lung infection, respiratory failure, and a cerebral thromboembolic event in one patient each. Treatment discontinuation due to TEAEs was reported in 36 patients (25.4\%), and these TEAEs were considered drug-related in 23 patients (16.2\%). Safety data from the 2-year follow-up of these patients remained consistent with the primary analysis, with no new or unexpected TEAEs reported over the longer treatment duration [36] (see Table 3).

In the phase II study of patients with DLBCL [55], treatment with copanlisib demonstrated a safety profile that was recognizable and consistent with the earlier studies in patients with malignant lymphoma. In the 67 patients enrolled and treated, the most common TEAEs were hypertension (40.3\%), diarrhea (37.3\%), hyperglycemia (32.8\%), nausea $(31.3 \%)$, and fatigue (28.4\%) (see Table 3). These events were also among the most frequent events that were considered drug-related in this population. There were 14 deaths (20.9\%), although none of these was deemed to be drug-related. Dose reductions and interruptions/delays due to TEAEs were reported in nine patients $(13.4 \%)$ and 34 patients $(50.7 \%)$, respectively, with TEAEs leading to permanent discontinuation in 17 patients $(25.4 \%)$. Serious TEAEs were observed in 44 patients (65.7\%).

Hyperglycemia (based on the Common Terminology Criteria for Adverse Events version 4 or lower) and hypertension constitute two of the most frequently reported TEAEs across all of the studies of copanlisib in patients with malignant lymphoma; hyperglycemia is a recognized class effect of PI3K inhibition [43-46]. Most cases of hyperglycemia and hypertension were of grade $\leq 3$ and were manageable. In the first-in-human phase I study of copanlisib, hyperglycemia was not a DLT for patients treated at the MTD level of $0.8 \mathrm{mg} / \mathrm{kg}$ and was considered transient, infusion-related, and manageable, with blood glucose values returning to baseline levels within $24 \mathrm{~h}$, and to normal levels before the next infusion [34]. Similarly, dose-dependent transient increases in plasma glucose were observed following copanlisib treatment in the pharmacodynamic study of copanlisib [60]. In the first-in-human study, hypertension was experienced by approximately one-third of patients, but was also observed to be transient, with increases in blood pressure returning to baseline levels within $24 \mathrm{~h}$ following first copanlisib infusion [34]. With hypertension not generally reported with other PI3K inhibitors, it has been proposed that the high 
Table 3 Summary of most common TEAEs in copanlisib clinical studies in patients with indolent and aggressive lymphoma

\begin{tabular}{|c|c|c|c|c|c|}
\hline \multirow[t]{2}{*}{ Study } & \multirow{2}{*}{$\begin{array}{l}\text { Phase I } \\
\text { NCT00962611 [34] }\end{array}$} & \multicolumn{4}{|l|}{ Phase II } \\
\hline & & $\begin{array}{l}\text { NCT01660451; part } \\
\text { A [52] }\end{array}$ & $\begin{array}{l}\text { CHRONOS-1, } \\
\text { NCT01660451; part } \\
\text { B [35] }\end{array}$ & $\begin{array}{l}\text { CHRONOS-1, } \\
\text { NCT01660451; part } \\
\text { B long-term follow-up } \\
\text { [36] }\end{array}$ & NCT02391116 [55] \\
\hline Number of patients & 9 & 84 & 142 & 142 & 67 \\
\hline Patient lymphoma type & $\begin{array}{l}\text { Indolent and aggres- } \\
\text { sive }\end{array}$ & $\begin{array}{l}\text { Indolent and aggres- } \\
\text { sive }\end{array}$ & Indolent & Indolent & Aggressive \\
\hline $\begin{array}{l}\text { AEs leading to dose } \\
\text { interruptions/modifi- } \\
\text { cations, } n(\%)\end{array}$ & $14(25.0)$ & $50(59.5) / 11(13.1)$ & $\begin{array}{l}105(73.9) / 37(26.1)^{\mathrm{b}} \\
8(5.6)^{\mathrm{c}}\end{array}$ & $116(81.7) / 40(28.2)$ & $34(50.7) / 9(13.4)$ \\
\hline Grade 5 AEs, $n(\%)$ & 0 & $10(11.9)$ & $6(4.2)$ & $6(4.2)$ & $14(20.9)$ \\
\hline \multicolumn{6}{|l|}{$\begin{array}{l}\text { AEs in } \geq 15 \% \text { of } \\
\text { patients (any grade), } \\
n(\%)\end{array}$} \\
\hline Hyperglycemia & $8(88.9)$ & $50(59.5)$ & $71(50.0)$ & $71(50.0)$ & $22(32.8)$ \\
\hline Nausea & $7(77.8)$ & $28(33.3)$ & $33(23.2)$ & $33(23.2)$ & $21(31.3)$ \\
\hline Hypertension & $3(33.3)$ & $46(54.8)$ & $43(30.3)$ & $42(29.6)$ & $27(40.3)$ \\
\hline Diarrhea & $3(33.3)$ & $34(40.5)$ & $48(33.8)$ & $50(35.2)$ & $25(37.3)$ \\
\hline $\begin{array}{l}\text { Decreased neutrophil } \\
\text { count/neutropenia }\end{array}$ & - & 29 (34.5) & $42(29.6)$ & $41(28.9)$ & $7(10.4)$ \\
\hline Fatigue & $3(33.3)$ & $41(48.8)$ & $43(30.3)$ & $37(26.1)$ & $19(28.4)$ \\
\hline Anemia & - & $24(28.6)$ & $22(15.5)$ & $25(17.6)$ & - \\
\hline Rash/desquamation & $2(22.2)$ & - & $18(12.7)^{\mathrm{d}}$ & - & $9(13.4)$ \\
\hline Oral mucositis & $3(33.3)$ & 19 (22.6) & $28(19.7)$ & - & - \\
\hline Lung infection & - & $17(20.2)$ & $30(21.1)$ & - & - \\
\hline Fever/pyrexia & - & $16(19.0)$ & $36(25.4)$ & $38(26.8)$ & $14(20.9)$ \\
\hline $\begin{array}{l}\text { Decreased platelet } \\
\text { count/thrombocyto- } \\
\text { penia }\end{array}$ & - & $15(17.9)$ & $29(20.4)$ & $20(14.1)$ & - \\
\hline Headache & - & $15(17.9)$ & - & - & $9(13.4)$ \\
\hline Urinary tract infection & - & $14(16.7)$ & - & - & - \\
\hline Dyspnea & - & $14(16.7)$ & - & - & $7(10.4)$ \\
\hline Constipation & - & $13(15.5)$ & $17(12.0)$ & $18(12.7)$ & $11(16.4)$ \\
\hline Cough & - & $10(11.9)$ & $23(16.2)$ & $27(19.0)$ & $12(17.9)$ \\
\hline
\end{tabular}

Top five AEs with the highest incidence per study are in bold

$A E$ adverse event, TEAE treatment-emergent adverse event

${ }^{a}$ Drug-related TEAEs are presented for this study

${ }^{\mathrm{b}}$ Dose reduction to $45 \mathrm{mg}$

${ }^{c}$ Dose reduction to $30 \mathrm{mg}$

${ }^{\mathrm{d}}$ Maculopapular

frequency of monitoring and the intravenous route of delivery with copanlisib may possibly account for some reported differences in TEAE profiles for PI3K inhibitors [46, 61], including the intravenous pan-PI3K/mTOR inhibitor pictilisib [62]. It has been suggested that the hypertension following copanlisib-mediated PI3K inhibition may be caused by dysregulation of endothelial-derived vasoconstrictors and vasodilators [63-66], or increased insulin levels [66, 67]. In the phase II, part A study, all hyperglycemia and hypertension events followed the same, predicted profile of being transient and infusion-related, with no patient discontinuing treatment as a result [52]. Post-infusion hyperglycemia and hypertension events were managed with insulin and antihypertensive treatments.

Similarly, hyperglycemia and hypertension were transient and were not a significant cause of treatment discontinuation in the CHRONOS-1 phase II, part B study [35]. In CHRONOS-1, infusion-related hyperglycemia was largely self-limiting, asymptomatic, and did not lead to significant discontinuation from treatment. Management 
of hyperglycemia with adequate hydration via oral fluids was satisfactory for most patients, although insulin or oral glucose-lowering agents (including metformin, a glucose cotransporter 2 inhibitor, and a dipeptidyl peptidase- 4 inhibitor) were used in patients with diabetes, those with persistent hyperglycemia despite adequate hydration, or those who were symptomatic. Safety data from the 2-year follow-up of the patients from the CHRONOS-1 phase II, part B study echoed the results from primary analysis, with hyperglycemic and hypertensive events remaining infusion-related, transitory, and manageable over the prolonged treatment duration, with no evidence of new or worsening events over time, and a trend toward a reduction in both TEAEs with longer treatment duration compared with earlier time points [36]. However, as reported in that study, this effect could be attributed to the longer-term and better management of these conditions, or possibly the development of tolerance. All reported incidences of hyperglycemic and hypertensive TEAEs in the phase II study of patients with DLBCL were grade $\leq 3$, transitory, and considered to be manageable in this population [55].

A key differentiator between the safety profiles of intravenous copanlisib and continuously administered oral PI3K inhibitors, including idelalisib and duvelisib, is the lower rate of severe gastrointestinal toxicities seen with copanlisib, such as colitis and severe liver enzyme elevations [36, $68,69]$. Idelalisib has also been shown to be associated with risk of inflammatory reactions, including hepatitis and pneumonitis, in addition to reactivation of cytomegalovirus and severe Pneumocystis jirovecii-related pulmonary infections [70], leading to five black box warnings [18]. Duvelisib carries four black box warnings, including fatal and/or serious infections, diarrhea or colitis, cutaneous reactions, and pneumonitis [17, 71]. Diarrhea has been frequently reported as a TEAE from studies with copanlisib treatment, although most events were mild in severity (grade < 4) [34, $35,52]$ and manageable with symptomatic treatment such as loperamide [52]. This was reflected in the 2-year longterm follow-up of the CHRONOS-1 phase II study with low overall rates of diarrhea and no evidence of worsening severity of diarrhea over time [36]. In addition, low rates of colitis and elevated liver enzymes (alanine transaminase and aspartate aminotransferase) have been observed with copanlisib. The clinical study results with copanlisib to date suggest that the intravenous route of administration and intermittent dosing schedule may together contribute toward an improved tolerability profile when compared with continuously dosed oral agents. However, although intermittent intravenous administration of copanlisib may provide beneficial outcomes and long-term tolerability, it will be important to consider the impact of the intravenous route of administration on convenience and logistics for therapy in some patients, particularly considering the current global coronavirus disease 2019 (COVID-19) pandemic. Logistic challenges with in-person clinic visits may require the development of alternative administration schedules in the future, and in the shorter term, methods of administering intravenous therapies in a way that patients can be safely treated and monitored while minimizing the risk of exposure to further illness are required.

\section{Copanlisib in Ongoing and Combination Studies}

Based on the clinical data to date, intravenous copanlisib has shown positive efficacy results and favorable tolerability in patients with indolent lymphoma $[35,36]$ in relation to the landscape of continuously administered oral PI3K inhibitors, warranting further clinical study as part of a combination regimen. Further study of copanlisib in this setting is also particularly relevant for populations with the highest unmet need, such as those with aggressive lymphomas, and it is desirable to improve upon the modest single-agent ORR for copanlisib in patients with DLBCL [55]; combination regimens may be better equipped to overcome limitations and inherent resistance to inhibition that may be observed with a monotherapy approach. With demonstrated on-target PI3K inhibitory activity, copanlisib is currently being evaluated as part of several different combination regimens as to whether the targeted activity of copanlisib can improve upon standard-of-care chemotherapy (see Table 4). Additional monotherapy trials are also ongoing in different patient populations, including those with solid tumors.

Two large, randomized, phase III studies are ongoing to explore the combinability of copanlisib with standard therapy for patients with indolent B cell lymphoma who have progressed on one or more lines of therapy. CHRONOS-3 (NCT02367040) is a phase III, randomized, double-blind, placebo-controlled study of copanlisib in combination with rituximab in patients with relapsed or refractory indolent lymphoma. Primary efficacy and safety data are expected to be reported in early 2021. CHRONOS-4 (NCT02626455) is a phase III, randomized, double-blind, placebo-controlled study that aims to evaluate the efficacy and safety of copanlisib in combination with rituximab and standard chemotherapy (R-B [rituximab plus bendamustine] or R-CHOP [rituximab plus cyclophosphamide, doxorubicin, vincristine, and prednisone]) in patients with relapsed $\mathrm{B}$ cell indolent lymphoma; preliminary data from the safety run-in phase to evaluate the feasibility of this combination have recently been reported [72]. The safety run-in phase was based on an open-label, two-dose level, $3+3$ design. R-B and R-CHOP were each tested at two copanlisib doses (45 and $60 \mathrm{mg}$ ), with a minimum of three and maximum of six patients evaluable for DLT at each dose level. Copanlisib 
Table 4 Summary of ongoing copanlisib studies

\begin{tabular}{|c|c|c|c|c|c|c|}
\hline Treatment(s) & Indication & Phase & Study name & Status & Country & NCT identifier \\
\hline Copanlisib & NHL & I & & Active, not recruiting & China & NCT03498430 \\
\hline Copanlisib & Advanced solid tumor & $\mathrm{I} / \mathrm{II}$ & & Recruiting & US & NCT03735628 \\
\hline Copanlisib & NHL & III & CHRONOS-2 & Active, not recruiting & Multinational & NCT02369016 \\
\hline Copanlisib & NHL & $\mathrm{Ib} / \mathrm{II}$ & & Active, not recruiting & Japan & NCT02342665 \\
\hline Copanlisib & Mixed malignant tumor & $\mathrm{I} / \mathrm{II}$ & & Recruiting & US & NCT03458728 \\
\hline Copanlisib & NHL & II & CHRONOS-1 & Active, not recruiting & Multinational & NCT01660451 \\
\hline Copanlisib and ibrutinib & MCL & $\mathrm{I} / \mathrm{II}$ & & Active, not recruiting & US & NCT03877055 \\
\hline Copanlisib and rituximab & MZL & II & & Recruiting & Austria, Germany & NCT03474744 \\
\hline Copanlisib and gemcitabine & $\begin{array}{l}\text { Mature T cell and NK cell } \\
\text { neoplasm }\end{array}$ & $\mathrm{I} / \mathrm{II}$ & & Active, not recruiting & Republic of Korea & NCT03052933 \\
\hline Copanlisib and nivolumab & Colorectal cancer & $\mathrm{I} / \mathrm{II}$ & & Recruiting & US & NCT03711058 \\
\hline Copanlisib and rucaparib & Prostate cancer & $\mathrm{I} / \mathrm{II}$ & & Recruiting & US & NCT04253262 \\
\hline $\begin{array}{l}\text { Copanlisib, bendamustine, } \\
\text { and rituximab }\end{array}$ & $\begin{array}{l}\text { Lymphoid leukemia, NHL, } \\
\text { CLL, SLL }\end{array}$ & II & & Recruiting & US & NCT04155840 \\
\hline Copanlisib and rituximab & NHL & III & CHRONOS-3 & Active, not recruiting & Multinational & NCT02367040 \\
\hline $\begin{array}{l}\text { Copanlisib and standard } \\
\text { immunochemotherapy }\end{array}$ & NHL & III & CHRONOS-4 & Active, not recruiting & Multinational & NCT02626455 \\
\hline $\begin{array}{l}\text { Copanlisib, gemcitabine, } \\
\text { carboplatin, dexametha- } \\
\text { sone, rituximab, and } \\
\text { pegfilgrastim }\end{array}$ & DLBCL, FL & $\mathrm{Ib}$ & & Recruiting & US & NCT04156828 \\
\hline Copanlisib and rogaratinib & $\begin{array}{l}\text { Advanced or metastatic solid } \\
\text { tumor }\end{array}$ & I & & Active, not recruiting & Multinational & NCT03517956 \\
\hline $\begin{array}{l}\text { Copanlisib, gemcitabine, and } \\
\text { cisplatin }\end{array}$ & Cholangiocarcinoma & II & & Active, not recruiting & US & NCT02631590 \\
\hline
\end{tabular}

$C L L$ chronic lymphocytic leukemia, $D L B C L$ diffuse large B cell lymphoma, $F L$ follicular lymphoma, $M C L$ mantle cell lymphoma, $M Z L$ marginal zone lymphoma, $N H L$ non-Hodgkin lymphoma, $N K$ natural killer, $S L L$ small lymphocytic lymphoma

was administered on days 1,8 , and 15 of a 28 -day cycle with $\mathrm{R}-\mathrm{B}$, or on days 1 and 8 of a 21-day cycle with R-CHOP, for up to six cycles. Copanlisib monotherapy was administered from cycle 7 for up to 12 months. There were no DLTs at either copanlisib dose level in either treatment arm, and the recommended phase III dose of copanlisib in combination with standard immunotherapy was defined as $60 \mathrm{mg}$ for both immunochemotherapy combinations. All patients in both treatment groups experienced TEAEs, the most common of which were decreased neutrophil count, nausea, decreased platelet count, and hyperglycemia, consistent with the known safety profile of copanlisib monotherapy [34, 35]; there were no cases of colitis. These preliminary data suggest that copanlisib in combination with standard immunochemotherapy has an acceptable safety and tolerability profile. The phase III portion of CHRONOS-4 is currently ongoing to assess the efficacy of copanlisib versus placebo in combination with immunochemotherapy, with an estimated primary completion date of 2022. Copanlisib is currently approved for use in patients who have been treated with two or more therapies; however, these studies have the potential to validate copanlisib as an effective treatment option for patients following initial relapse.

\section{Conclusions and Future Perspectives}

To date, phase I and phase II studies of copanlisib in patients with malignant lymphoma have demonstrated durable and sustained anti-tumor activity, with a distinct yet manageable safety profile. Durable and rapid objective responses have been observed in patients with heavily pre-treated indolent lymphoma, particularly FL and MZL. Based on this, copanlisib received breakthrough designation for pretreated MZL in 2019. Responses to copanlisib have shown to be sustained, even enhanced, in patients with indolent lymphoma, with prolonged treatment [36]. Copanlisib has demonstrated robust activity in patients with FL with POD24, a subset who are deemed to have the highest unmet need. The results to date support the feasibility of copanlisib treatment and support its use in heavily pre-treated patients with indolent lymphoma. Patients with aggressive lymphoma are difficult to treat, with treatment options typically being very limited; there is an urgent need for novel therapeutic strategies. Copanlisib has demonstrated antilymphoma activity in a phase II study, with favorable efficacy in patients with DLBCL (an overall ORR of $19.4 \%$ and an overall DCR of $40.3 \%$ ) [55]. It is anticipated that ongoing 
studies of copanlisib in combination with standard-of-care chemotherapy will provide additional therapeutic strategies in these underserved populations.

Key considerations for administering copanlisib therapy include awareness of the known safety profile, the route of administration, and preferences regarding infusion at the treating center. The most frequent TEAEs of transient hyperglycemia and hypertension are largely self-limiting and have been demonstrated to resolve following copanlisib infusion; recommendations for management include glucose-lowering medications and short-acting anti-hypertensive medications, respectively. For patients with blood pressure above $150 / 90 \mathrm{mmHg}$ while on copanlisib treatment, it is recommended that anti-hypertensive medication continues until there are two consecutive readings of less than 150/90 $\mathrm{mmHg}$ [71]. Treatment-emergent diarrhea is also common with copanlisib therapy, although usually not severe, and recommendations are available on managing diarrhea during copanlisib therapy, initially focusing on conservative management [71]. The intravenous route of administration and intermittent schedule may support the favorable tolerability profile of copanlisib, but oral therapies may be preferred in some treating centers over others. However, oral therapies pose unique challenges to treatment adherence for patients with lymphoma, in addition to potentially contributing to higher out-of-pocket patient costs compared with intravenous therapies, which may present a barrier to access [73, 74]. It should be noted, however, that the logistics and convenience of intravenous administration are likely to be affected by the current global COVID-19 pandemic.

In the current landscape of FDA-approved therapies in advanced malignant lymphoma, copanlisib is the only intravenously administered PI3K inhibitor agent available. With the ongoing development of further oral PI3K inhibitors in this setting, results from clinical studies of intravenous copanlisib confirming its feasibility in combination with immunochemotherapy regimens may offer urgently needed additional therapeutic options for pre-treated patients with malignant lymphoma in the second-line setting, as well as continuing to support the use of copanlisib in patients with relapsed FL and, pending FDA approval, MZL, in the thirdline setting.

Acknowledgements Jack Adams, MSc., at Complete HealthVizion (Manchester, UK) provided medical writing assistance with this paper, based on detailed discussion and feedback from all the authors. This assistance was funded by Bayer AG.

\section{Declarations}

Funding Bayer AG provided funding support for the medical writing assistance received for this manuscript.
Conflicts of interest JM has received consulting fees from Alexion, Bayer, BeiGene, Bristol-Myers Squibb, Fosun Kite, Gilead/Kite Pharma, Innovent, Janssen, Juno/Celgene, Kyowa, Pfizer, Pharmacyclics, and Seattle Genetics; research funding from Bayer, Celgene, Genentech, Gilead/Kite Pharma, Incyte, Janssen, Merck, Millennium, Portola, Pharmacyclics, and Seattle Genetics; honoraria from Kyowa and Seattle Genetics; and speaker's bureau fees from AbbVie, Acrotech/ Aurobindo, AstraZeneca, Bayer, BeiGene, Celgene/Bristol-Myers Squibb, Genentech/Roche, Gilead/Kite Pharma, Kyowa, Pharmacyclics/Janssen, Seattle Genetics, and Verastem. GAF reports consultancy and lecturing fees from AbbVie, AstraZeneca, Bayer, Janssen, and Roche. LJN has received honoraria from Bayer, Bristol-Myers Squibb/ Celgene, Genentech, Janssen, Kite/Gilead, Novartis, Pfizer, and TG Therapeutics; and research support from Bristol-Myers Squibb/Celgene, Genentech, Janssen, Novartis, Pfizer, and TG Therapeutics.

Ethics approval Not applicable.

Consent to participate Not applicable.

Consent for publication Not applicable.

Availability of data and material Not applicable.

Code availability Not applicable.

Authors' contributions All authors provided insight into the development of this manuscript and provided critical review of each draft. All authors read and approved the final manuscript.

Open Access This article is licensed under a Creative Commons Attribution-NonCommercial 4.0 International License, which permits any non-commercial use, sharing, adaptation, distribution and reproduction in any medium or format, as long as you give appropriate credit to the original author(s) and the source, provide a link to the Creative Commons licence, and indicate if changes were made. The images or other third party material in this article are included in the article's Creative Commons licence, unless indicated otherwise in a credit line to the material. If material is not included in the article's Creative Commons licence and your intended use is not permitted by statutory regulation or exceeds the permitted use, you will need to obtain permission directly from the copyright holder. To view a copy of this licence, visit http://creativecommons.org/licenses/by-nc/4.0/.

\section{References}

1. Engelman JA, Luo J, Cantley LC. The evolution of phosphatidylinositol 3-kinases as regulators of growth and metabolism. Nat Rev Genet. 2006;7:606-19.

2. Liu P, Cheng H, Roberts TM, Zhao JJ. Targeting the phosphoinositide 3-kinase pathway in cancer. Nat Rev Drug Discov. 2009;8:627-44.

3. Shepherd PR. Mechanisms regulating phosphoinositide 3-kinase signalling in insulin-sensitive tissues. Acta Physiol Scand. 2005;183:3-12.

4. Vogt PK, Hart JR, Gymnopoulos M, Jiang H, Kang S, Bader AG, et al. Phosphatidylinositol 3-kinase: the oncoprotein. Curr Top Microbiol Immunol. 2010;347:79-104.

5. Hennessy BT, Smith DL, Ram PT, Lu Y, Mills GB. Exploiting the PI3K/AKT pathway for cancer drug discovery. Nat Rev Drug Discov. 2005;4:988-1004. 
6. Schatz JH. Targeting the PI3K/AKT/mTOR pathway in nonHodgkin's lymphoma: results, biology, and development strategies. Curr Oncol Rep. 2011;13:398.

7. Nogai H, Dörken B, Lenz G. Pathogenesis of non-Hodgkin's lymphoma. J Clin Oncol. 2011;29:1803-11.

8. Lunning MA, Vose JM. Management of indolent lymphoma: where are we now and where are we going. Blood Rev. 2012;26:279-88.

9. Dada R. Diagnosis and management of follicular lymphoma: a comprehensive review. Eur J Haematol. 2019;103:152-63.

10. Casulo C, Byrtek M, Dawson KL, Zhou X, Farber CM, Flowers $\mathrm{CR}$, et al. Early relapse of follicular lymphoma after rituximab plus cyclophosphamide, doxorubicin, vincristine, and prednisone defines patients at high risk for death: an analysis from the National LymphoCare Study. J Clin Oncol. 2015;33:2516-22.

11. Jurinovic V, Kridel R, Staiger AM, Szczepanowski M, Horn H, Dreyling $\mathrm{MH}$, et al. Clinicogenetic risk models predict early progression of follicular lymphoma after first-line immunochemotherapy. Blood. 2016;128:1112-20.

12. Casulo C, Barr PM. How I treat early-relapsing follicular lymphoma. Blood. 2019;133:1540-7.

13. Casulo C, Barr PM. How I treat in brief: early relapsing follicular lymphoma. https://www.ashclinicalnews.org/education/how-itreat-in-brief/treat-brief-early-relapsing-follicular-lymphoma/. Accessed 13 July 2020.

14. Ma Y, Zhang P, Gao Y, Fan H, Zhang M, Wu J. Evaluation of AKT phosphorylation and PTEN loss and their correlation with the resistance of rituximab in DLBCL. Int J Clin Exp Pathol. 2015;8:14875-84.

15. Xu ZZ, Xia ZG, Wang AH, Wang WF, Liu ZY, Chen LY, et al. Activation of the PI3K/AKT/mTOR pathway in diffuse large B cell lymphoma: clinical significance and inhibitory effect of rituximab. Ann Hematol. 2013;92:1351-8.

16. Yahiaoui OI, Nunès JA, Castanier C, Devillier R, Broussais F, Fabre AJ, et al. Constitutive AKT activation in follicular lymphoma. BMC Cancer. 2014;14:565.

17. US Food and Drug Administration. COPIKTRA (duvelisib) highlights of prescribing information. 2018. https://www.acces sdata.fda.gov/drugsatfda_docs/label/2018/211155s000lbl.pdf. Accessed 13 July 2020.

18. US Food and Drug Administration. ZYDELIG (idelalisib) highlights of prescribing information. 2014. https://www.accessdata .fda.gov/drugsatfda_docs/label/2014/206545lbl.pdf. Accessed 13 July 2020.

19. US Food and Drug Administration. ALIQOPA (copanlisib) highlights of prescribing information. 2020. https://www.acces sdata.fda.gov/drugsatfda_docs/label/2020/209936s004lbl.pdf. Accessed 13 July 2020.

20. Greenwell IB, Ip A, Cohen JB. PI3K inhibitors: understanding toxicity mechanisms and management. Oncology. 2017;31:821-8.

21. Coutré SE, Barrientos JC, Brown JR, de Vos S, Furman RR, Keating MJ, et al. Management of adverse events associated with idelalisib treatment: expert panel opinion. Leuk Lymphoma. 2015;56:2779-86.

22. US Food and Drug Administration. FDA alerts healthcare professionals about clinical trials with Zydelig (idelalisib) in combination with other cancer medicines. 2016. http://www.fda.gov/Drugs /DrugSafety/ucm490618.htm. Accessed 13 July 2020.

23. Coutre SE, Flinn IW, de Vos S, Barrientos JC, Schreeder MT, Wagner-Johnson ND, et al. Idelalisib in combination with rituximab or bendamustine or both in patients with relapsed/refractory chronic lymphocytic leukemia. Hemasphere. 2018;2:e39.

24. Flinn IW, Cherry MA, Maris MB, Matous JV, Berdeja JG, Patel M. Combination trial of duvelisib (IPI-145) with rituximab or bendamustine/rituximab in patients with non-Hodgkin lymphoma or chronic lymphocytic leukemia. Am J Hematol. 2019;94:1325-34.
25. Fowler NH, Samaniego F, Jurczak W, Lech-Maranda E, Ghosh $\mathrm{N}$, Patten $\mathrm{P}$, et al. Umbralisib monotherapy demonstrates efficacy and safety in patients with relapsed/refractory marginal zone lymphoma: a multicenter, open label, registration directed phase II study. J Clin Oncol. 2019;37(15_suppl):7506.

26. Coleman M, Belada D, Casasnovas RO, Gressin R, Lee HP, Mehta A, et al. Phase 2 study of parsaclisib (INCB050465), a highly selective, next-generation PI3Kס inhibitor, in relapsed or refractory diffuse large B-cell lymphoma (CITADEL-202). Leuk Lymphoma. 2021;62(2):368-76.

27. Hirayama AV, Gauthier J, Hay KA, Voutsinas JM, Wu Q, Pender BS, et al. High rate of durable complete remission in follicular lymphoma after CD19 CAR-T cell immunotherapy. Blood. 2019;134:636-40.

28. Jacobson CA, Chavez JC, Sehgal AR, William BM, Munoz J, Salles GA, et al. Interim analysis of ZUMA-5: a phase II study of axicabtagene ciloleucel (axi-cel) in patients (pts) with relapsed/ refractory indolent non-Hodgkin lymphoma (R/R iNHL). J Clin Oncol. 2020;38(15_suppl):8008.

29. Neelapu SS, Locke FL, Bartlett NL, Lekakis LJ, Miklos DB, Jacobson CA, et al. Axicabtagene ciloleucel CAR T-cell therapy in refractory large B-cell lymphoma. N Engl J Med. 2017;377:2531-44.

30. Schuster SJ, Bartlett NL, Assouline S, Yoon SS, Bosch FX, Sehn $\mathrm{LH}$, et al. Mosunetuzumab induces complete remissions in poor prognosis non-Hodgkin lymphoma patients, including those who are resistant to or relapsing after chimeric antigen receptor T-cell (CAR-T) therapies, and is active in treatment through multiple lines. Blood. 2019;134(1_suppl):6.

31. Hutchings M, Lugtenburg P, Mous R, Clausen MR, Chamuleau M, Linton K, et al. Epcoritamab (GEN3013; DuoBody-CD3×CD20) to induce complete response in patients with relapsed/refractory B-cell non-Hodgkin lymphoma (B-NHL): complete dose escalation data and efficacy results from a phase I/II trial. J Clin Oncol. 2020;38(15_suppl):8009.

32. US Food and Drug Administration. FDA granted accelerated approval to tazemetostat for follicular lymphoma. 2020. https:// www.fda.gov/drugs/fda-granted-accelerated-approval-tazemetost at-follicular-lymphoma. Accessed 13 July 2020.

33. Liu N, Rowley BR, Bull CO, Schneider C, Haegebarth A, Schatz CA, et al. BAY 80-6946 is a highly selective intravenous PI3K inhibitor with potent $\mathrm{p} 110 \alpha$ and $\mathrm{p} 110 \delta$ activities in tumor cell lines and xenograft models. Mol Cancer Ther. 2013;12:2319-30.

34. Patnaik A, Appleman LJ, Tolcher AW, Papadopoulos KP, Beeram M, Rasco DW, et al. First-in-human phase I study of copanlisib (BAY 80-6946), an intravenous pan-class I phosphatidylinositol 3-kinase inhibitor, in patients with advanced solid tumors and non-Hodgkin's lymphomas. Ann Oncol. 2016;27:1928-40.

35. Dreyling M, Santoro A, Mollica L, Leppä S, Follows GA, Lenz $\mathrm{G}$, et al. Phosphatidylinositol 3-kinase inhibition by copanlisib in relapsed or refractory indolent lymphoma. J Clin Oncol. 2017;35:3898-905.

36. Dreyling M, Santoro A, Mollica L, Leppä S, Follows G, Lenz G, et al. Long-term safety and efficacy of the PI3K inhibitor copanlisib in patients with relapsed or refractory indolent lymphoma: 2-year follow-up of the CHRONOS-1 study. Am J Hematol. 2020;95:362-71.

37. US Food and Drug Administration. ALIQOPA (copanlisib) highlights of prescribing information. 2017. https://www.acces sdata.fda.gov/drugsatfda_docs/label/2017/209936s0001bl.pdf. Accessed 13 July 2020.

38. Liu N, Haegebarth A, Bull C, Schatz C, Wiehr S, Pichler BJ, et al. BAY 80-6946, a highly potent and efficacious PI3K class I inhibitor, induces complete tumor regression or tumor stasis in tumor xenograft models with PIK3CA mutant or PTEN deletion. Cancer Res. 2010;70(8_suppl):4478. 
39. Molinaro A, Becattini B, Mazzoli A, Bleve A, Radici L, Maxvall $\mathrm{I}$, et al. Insulin-driven PI3K-AKT signaling in the hepatocyte is mediated by redundant $\mathrm{PI} 3 \mathrm{~K} \alpha$ and $\mathrm{PI} 3 \mathrm{~K} \beta$ activities and is promoted by RAS. Cell Metab. 2019;29:1400-9.e5.

40. Knight ZA, Gonzalez B, Feldman ME, Zunder ER, Goldenberg DD, Williams $\mathrm{O}$, et al. A pharmacological map of the PI3-K family defines a role for $\mathrm{p} 110 \alpha$ in insulin signaling. Cell. 2006;125:733-47.

41. Huang X, Liu G, Guo J, Su Z. The PI3K/AKT pathway in obesity and type 2 diabetes. Int J Biol Sci. 2018;14:1483-96.

42. Sopasakis VR, Liu P, Suzuki R, Kondo T, Winnay J, Tran TT, et al. Specific roles of the $\mathrm{p} 110 \alpha$ isoform of phosphatidylinsositol 3-kinase in hepatic insulin signaling and metabolic regulation. Cell Metab. 2010;11:220-30.

43. Khan KH, Wong M, Rihawi K, Bodla S, Morganstein D, Banerji $\mathrm{U}$, et al. Hyperglycemia and phosphatidylinositol 3-kinase/protein kinase $\mathrm{B} /$ mammalian target of rapamycin (PI3K/AKT/mTOR) inhibitors in phase I trials: incidence, predictive factors, and management. Oncologist. 2016;21:855-60.

44. Juric D, Krop I, Ramanathan RK, Wilson TR, Ware JA, Sanabria Bohorquez SM, et al. Phase I dose-escalation study of taselisib, an oral PI3K inhibitor, in patients with advanced solid tumors. Cancer Discov. 2017;7:704-15.

45. Mayer IA, Abramson VG, Formisano L, Balko JM, Estrada MV, Sanders ME, et al. A Phase Ib study of alpelisib (BYL719), a $\mathrm{PI} 3 \mathrm{~K} \alpha$-specific inhibitor, with letrozole in $\mathrm{ER}^{+} / \mathrm{HER} 2^{-}$metastatic breast cancer. Clin Cancer Res. 2017;23:26-34.

46. Bendell JC, Rodon J, Burris HA, de Jonge M, Verweij J, Birle D, et al. Phase I, dose-escalation study of BKM120, an oral pan-class I PI3K inhibitor, in patients with advanced solid tumors. J Clin Oncol. 2012;30:282-90.

47. Morschhauser F, Machiels JP, Salles G, Rottey S, Rule SAJ, Cunningham D, et al. On-target pharmacodynamic activity of the PI3K inhibitor copanlisib in paired biopsies from patients with malignant lymphoma and advanced solid tumors. Mol Cancer Ther. 2020;19:468-78.

48. Han S, Zhang C, Li Q, Dong J, Liu Y, Huang Y, et al. Tumourinfiltrating $\mathrm{CD}^{+}$and $\mathrm{CD}^{+}$lymphocytes as predictors of clinical outcome in glioma. Br J Cancer. 2014;110:2560-8.

49. Wang K, Shen T, Siegal GP, Wei S. The CD4/CD8 ratio of tumor-infiltrating lymphocytes at the tumor-host interface has prognostic value in triple-negative breast cancer. Hum Pathol. 2017;69:110-7.

50. Schulze AB, Evers G, Görlich D, Mohr M, Marra A, Hillejan L, et al. Tumor infiltrating T cells influence prognosis in stage I-III non-small cell lung cancer. J Thorac Dis. 2020;12:1824-42.

51. Patnaik A, Appleman LJ, Mountz JM, Ramanathan RK, Beeram M, Tolcher AW, et al. A first-in-human Phase I study of intravenous PI3K inhibitor BAY 80-6946 in patients with advanced solid tumors: results of dose-escalation phase. J Clin Oncol. 2011;29(15_suppl):3035.

52. Dreyling M, Morschhauser F, Bouabdallah K, Bron D, Cunningham D, Assouline SE, et al. Phase II study of copanlisib, a PI3K inhibitor, in relapsed or refractory, indolent or aggressive lymphoma. Ann Oncol. 2017;28:2169-78.

53. Mustafa Ali M, Rybicki L, Nomani L, Rouphail B, Dean RM, Hill BT, et al. Grade 3 follicular lymphoma: outcomes in the rituximab era. Clin Lymphoma Myeloma Leuk. 2017;17:797-803.

54. Shah NN, Szabo A, Saba R, Strelec L, Kodali D, Vaughn JL, et al. Multicenter analysis of advanced stage grade 3A follicular lymphoma outcomes by frontline treatment regimen. Clin Lymphoma Myeloma Leuk. 2019;19:95-102.

55. Lenz G, Hawkes E, Verhoef G, Haioun C, Thye Lim S, Seog Heo $\mathrm{D}$, et al. Single-agent activity of phosphatidylinositol 3-kinase inhibition with copanlisib in patients with molecularly defined relapsed or refractory diffuse large B-cell lymphoma. Leukemia. 2020;34:2184-97.

56. Lenz G, Staudt LM. Aggressive lymphomas. N Engl J Med. 2010;362:1417-29.

57. Lenz G, Wright G, Dave SS, Xiao W, Powell J, Zhao H, et al. Stromal gene signatures in large B-cell lymphomas. N Engl J Med. 2008;359:2313-23.

58. Erdmann T, Klener P, Lynch JT, Grau M, Vočková P, Molinsky $\mathrm{J}$, et al. Sensitivity to PI3K and AKT inhibitors is mediated by divergent molecular mechanisms in subtypes of DLBCL. Blood. 2017;130:310-22.

59. Paul J, Soujon M, Wengner AM, Zitzmann-Kolbe S, Sturz A, Haike K, et al. Simultaneous inhibition of PI $3 \mathrm{~K} \delta$ and PI3K $\alpha$ induces $\mathrm{ABC}-\mathrm{DLBCL}$ regression by blocking BCR-dependent and -independent activation of NF- $\mathrm{\kappa B}$ and AKT. Cancer Cell. 2017;31:64-78.

60. Morschhauser F, Awada A, Machiels JP, Salles GA, Rottey S, Rule S, et al. Pharmacodynamic study of copanlisib in patients with non-Hodgkin's lymphoma and advanced solid tumors: confirmation of on-target PI3K inhibitory activity. Blood. 2017;130(1_suppl):1256.

61. Shapiro GI, Bell-McGuinn KM, Molina JR, Bendell J, Spicer J, Kwak EL, et al. First-in-human study of PF-05212384 (PKI587), a small-molecule, intravenous, dual inhibitor of PI3K and mTOR in patients with advanced cancer. Clin Cancer Res. 2015;21:1888-95.

62. Sarker D, Ang JE, Baird R, Kristeleit R, Shah K, Moreno V, et al. First-in-human phase I study of pictilisib (GDC-0941), a potent pan-class I phosphatidylinositol-3-kinase (PI3K) inhibitor, in patients with advanced solid tumors. Clin Cancer Res. 2015;21:77-86.

63. Montagnani M, Chen H, Barr VA, Quon MJ. Insulin-stimulated activation of eNOS is independent of $\mathrm{Ca}^{2+}$ but requires phosphorylation by Akt at $\operatorname{Ser}^{1179}$. J Biol Chem. 2001;276:30392-8.

64. Quaschning T, Voss F, Relle K, Kalk P, Vignon-Zellweger N, $\mathrm{Pfab} \mathrm{T}$, et al. Lack of endothelial nitric oxide synthase promotes endothelin-induced hypertension: lessons from endothelin-1 transgenic/endothelial nitric oxide synthase knockout mice. J Am Soc Nephrol. 2007;18:730-40.

65. Ha JM, Kim YW, Lee DH, Yun SJ, Kim EK, Hye Jin I, et al. Regulation of arterial blood pressure by Akt1-dependent vascular relaxation. J Mol Med (Berl). 2011;89:1253-60.

66. Symons JD, McMillin SL, Riehle C, Tanner J, Palionyte M, Hillas $\mathrm{E}$, et al. Contribution of insulin and Akt1 signaling to endothelial nitric oxide synthase in the regulation of endothelial function and blood pressure. Circ Res. 2009;104:1085-94.

67. Yu Q, Gao F, Ma XL. Insulin says NO to cardiovascular disease. Cardiovasc Res. 2011;89:516-24.

68. Weidner AS, Panarelli NC, Geyer JT, Bhavsar EB, Furman RR, Leonard JP, et al. Idelalisib-associated colitis: histologic findings in 14 patients. Am J Surg Pathol. 2015;39:1661-7.

69. Flinn IW, Patel M, Oki Y, Horwitz S, Foss FF, Allen K, et al. Duvelisib, an oral dual PI3K- $\delta, \gamma$ inhibitor, shows clinical activity in indolent non-Hodgkin lymphoma in a phase 1 study. Am J Hematol. 2018;93:1311-7.

70. Mensah FA, Blaize JP, Bryan LJ. Spotlight on copanlisib and its potential in the treatment of relapsed/refractory follicular lymphoma: evidence to date. Onco Targets Ther. 2018;11:4817-27.

71. Narkhede M, Cheson BD. Copanlisib in the treatment of nonHodgkin lymphoma. Future Oncol. 2020;16:1947-55.

72. Zinzani PL, Dreyling M, Leppä S, Santoro A, Pedersen M, Buvaylo V, et al. Feasibility of combining the phosphatidylinositol 3-kinase inhibitor copanlisib with rituximab-based immunochemotherapy in patients with relapsed indolent non-Hodgkin lymphoma. 25th Congress of the European Hematology Association (Virtual Edition), June 11-14, 2020. Poster EP1171. 
73. Benjamin L, Buthion V, Vidal-Trécan G, Briot P. Impact of the healthcare payment system on patient access to oral anticancer drugs: an illustration from the French and United States contexts. BMC Health Serv Res. 2014;14:274.
74. Zackon AYL, Ayers AA, Yeager KA, Somma ML, Friedberg JW, Flowers CR, et al. Maximizing the effectiveness of oral therapies in lymphoid cancers: research gaps and unmet needs. Leuk Lymphoma. 2019;60:2356-64. 